\title{
CPW Fed Rectangular Slot Antenna for Wideband Applications
}

\author{
T. Shanmuganantham \\ Assistant Professor \\ Department of Electronics Engineering \\ Pondicherry University, Pondicherry
}

\author{
S. Raghavan \\ Professor \\ Department of Electronics \& Communication Engg. \\ National Institute of Technology, Trichy
}

\begin{abstract}
A Coplanar Waveguide (CPW) fed slot antenna for wideband applications is presented. The slot antenna is excited by a CPW with a U-shaped tuning stub. The simulations were performed for $\mathrm{S}_{11}$ and the radiation patterns. The structure was redesigned for the facilities available in the fabrication unit and then the parameters were measured.
\end{abstract}

\section{General Terms}

Return loss, radiation pattern, slot antenna.

\section{Keywords}

Antenna, CPW, MEMS, wide-band.

\section{INTRODUCTION}

Microstrip slot antennas are used in satellite and communication application because of its lightweight and ease of integration with monolithic microwave integrated circuits. But the drawback for Microstrip slot antennas is narrow bandwidth. This can be rectified by using a $U$ shaped tuning stub under the slot [1]. But alignment error can occur since slot and stub are on opposite sides of the substrate. To avoid this CPW feed can be used so that both stub and slot will be on one side of the substrate. In this paper an attempt is made to reduce the size of the antenna. It has been shown that [2] use of tuning stubs enhance impedance bandwidth. Incorporating U shaped tuning stub has shown a further increase in impedance bandwidth [3]. The simulation software used is IE3D [4].

\section{ANTENNA STRUCTURE AND DESIGN}

The proposed reduced size CPW fed slot antenna is shown in Fig1. The size of the antenna is $6 \mathrm{~cm} X 6 \mathrm{~cm}$. The substrate has a dielectric constant of $\varepsilon r=3.38$ and thickness of $h=0.813 \mathrm{~mm}$ $\left(0.017 \lambda_{\mathrm{o}}\right)$ where $\lambda_{\mathrm{o}}$ is the free space wavelength at the center frequency $6.4 \mathrm{GHz}$. The rectangular slot has a width $\mathrm{W}=32.2 \mathrm{~mm}\left(0.69 \lambda_{\mathrm{o}}\right)$ and length $\mathrm{L}=21.1 \mathrm{~mm}\left(0.45 \lambda_{\mathrm{o}}\right)$. A $50 \Omega$ coplanar waveguide with slot width $(0.125 \mathrm{~mm})$ and center conductor width $(1.88 \mathrm{~mm})$ is used.

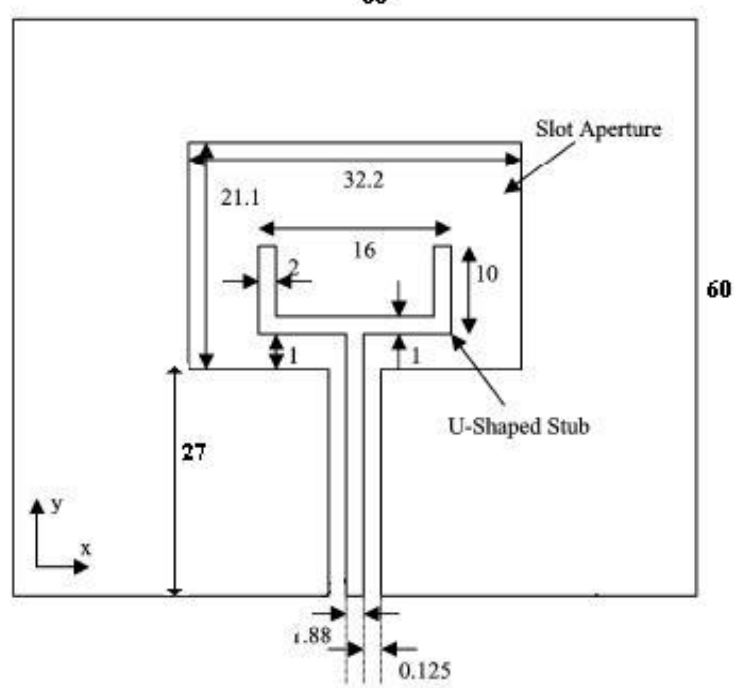

Fig.1 Dimensions of the CPW fed rectangular slot antenna (units in mm)

A U shaped tuning stub embedded Fig.1 Dimensions of the CPW fed rectangular slot antenna (units in $\mathrm{mm}$ ) within the slot terminates the CPW feed. The stub has a total length of $16 \mathrm{~mm}$ and width $10 \mathrm{~mm}[3]$.

\section{SIMULATION RESULTS}

The return loss plot for antenna in Fig.1 is shown in Fig.2. The impedance bandwidth criterion used here is $\mathrm{S}_{11}<-10 \mathrm{~dB}$. The impedance bandwidth of the antenna in Fig. 1 is $6.78 \mathrm{GHz}$ $(106 \%)$. The wide bandwidths are due to the multiple resonances introduced by the combination of the rectangular slot and the U- shaped stubs. The resonant frequency and bandwidth are controlled by the size of the rectangular slot and tuning stub. The reduced dimension structure shows a return loss performance equal to that of which is shown in [3]. So an achievement from 100 sq.cm to 36 sq.cm is achieved. 


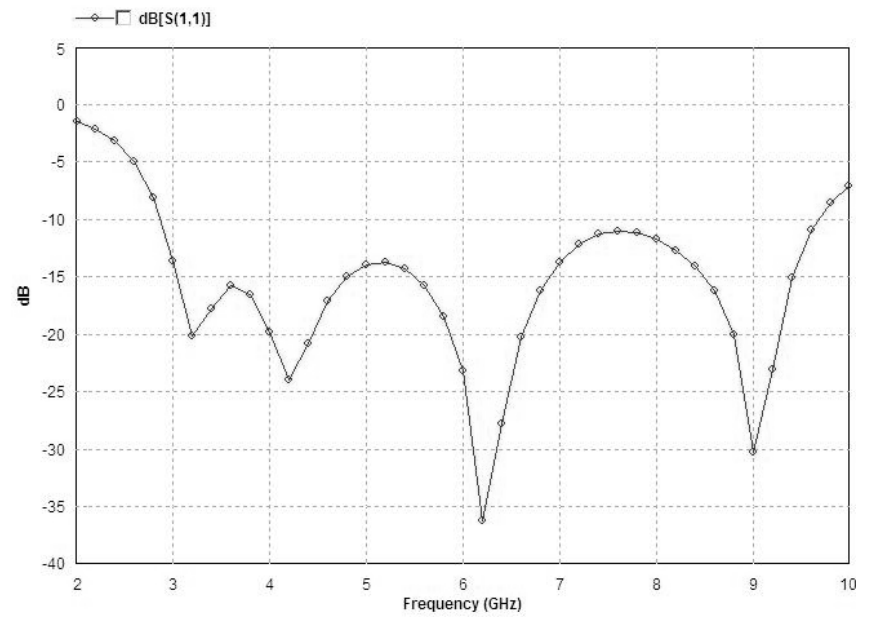

Fig.2. Simulated return loss for the structure shown in

Fig.1

The use of tuning stubs controls the coupling between the CPW feed line and slot and hence increases the impedance bandwidth.

\section{FABRICATION DETAILS}

For meeting the requirements of the fabrication unit the structure was redesigned and simulated. The redesigned structure had the same overall dimension but a change in substrate of $\varepsilon r=3.5$ and thickness of $\mathrm{h}=0.737 \mathrm{~mm}$.

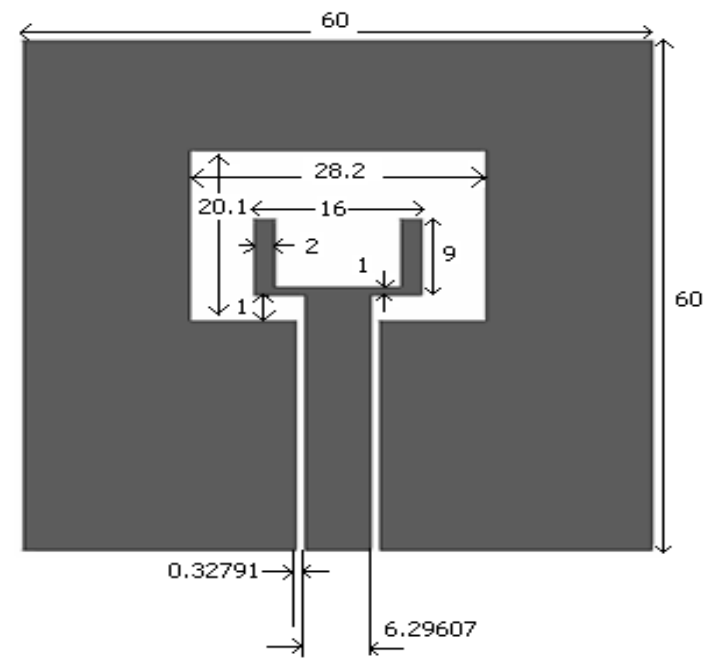

Fig.3. Dimensioned layout of the structure fabricated

The fabricated structure is shown in Fig.4 and the dimensioned layout is shown in Fig.3.

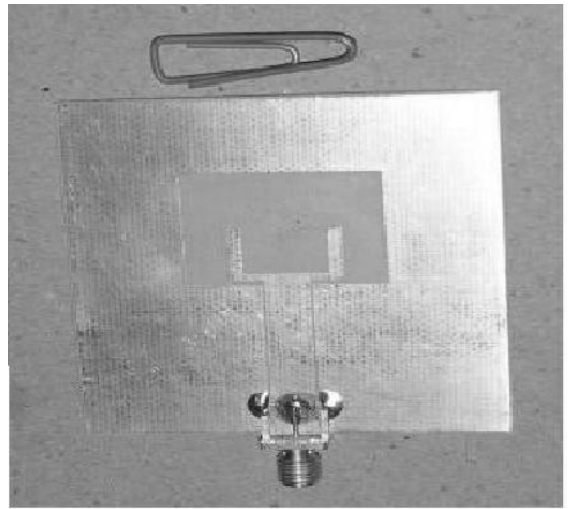

Fig4. Photograph of the fabricated structure

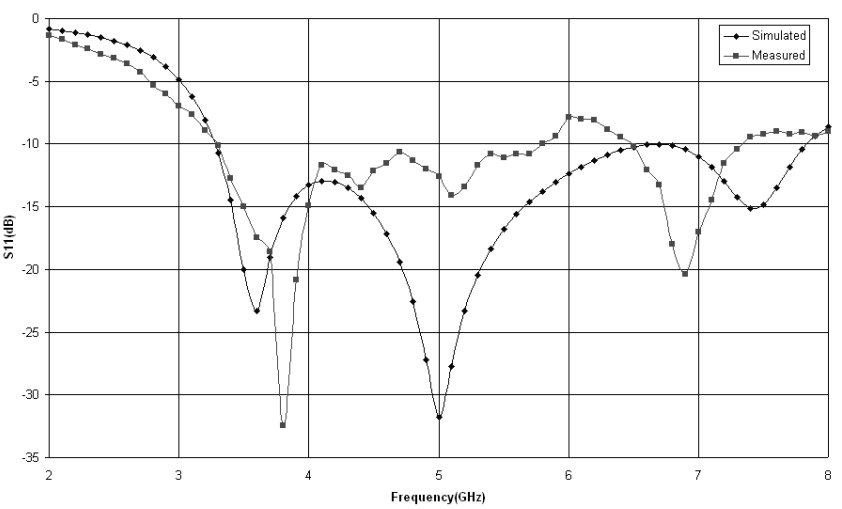

Fig.5 Comparison of the measured and simulated response

The CPW feed was also redesigned by proportionally increasing the center conductor width and spacing using the CPW characteristics to yield a $50 \Omega$ feed line. The simulated and measured return losses are compared in Fig.5. The simulated bandwidth was nearly $4.6 \mathrm{GHz}$ with a center frequency of $5.6 \mathrm{GHz}$. The measured response showed two bands. One band of bandwidth $2.5 \mathrm{GHz}$ and the other of $800 \mathrm{MHz}$. This can occur because the simulated response was near to the $-10 \mathrm{~dB}$ mark near $6.7 \mathrm{GHz}$ which could not achieved due to the dimension tolerance of the fabrication unit as well as the measuring environment which could not be predicted in the simulation tools. The radiation patterns of the structure were measured at the frequency of maximum tuning which is $3.8 \mathrm{GHz}$ and it is compared with the simulated radiation patterns below in Fig.6. (E-plane) and Fig.7 (HPlane). 


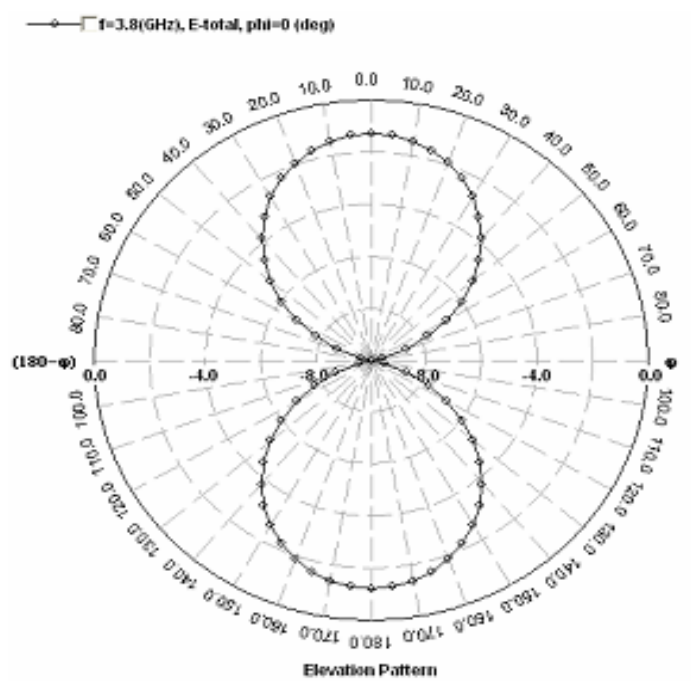

(a)

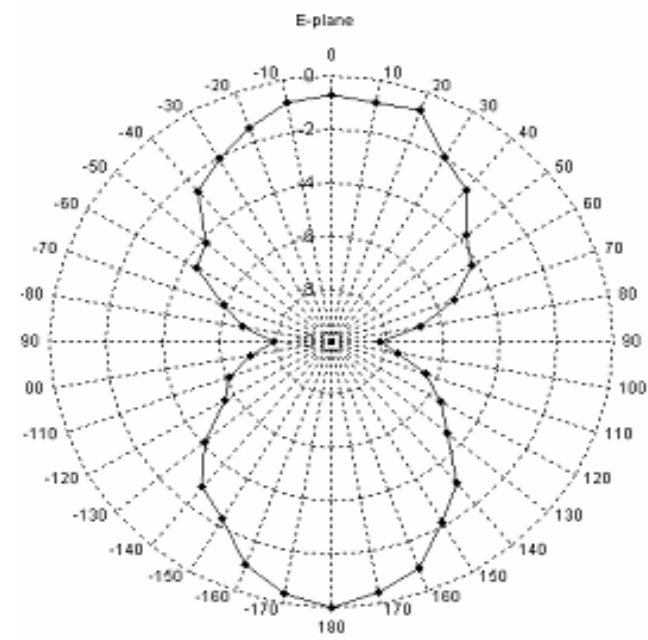

(b)

Fig.6 E-plane radiation pattern (a) Simulated (b) Measured

The 3-dB beamwidth of the antenna has been observed to be $86^{\circ}$ by simulation and the measured pattern gave $80^{\circ}$ beamwidth in the E-plane. In H-plane the beamwidth was observed as $72^{\circ}$ by simulation and the measured pattern gave $60^{\circ}$.

\section{CONCLUSION}

A small sized wide-band Coplanar Waveguide fed rectangular slot antenna on a thin substrate was studied. The wide bandwidth was achieved by the use of a U-shaped tuning stub. The structure was fabricated and tested for the impedance bandwidth and the radiation pattern. The radiation patterns measured showed reasonable agreement with the simulations. The impedance bandwidth of the antenna was not achieved as expected due to the limitations of the fabrication unit. The Ushaped stub can be reconfigured using MEMS switches for controlling the bandwidth and also the structure can be grounded to make the radiation pattern unidirectional.

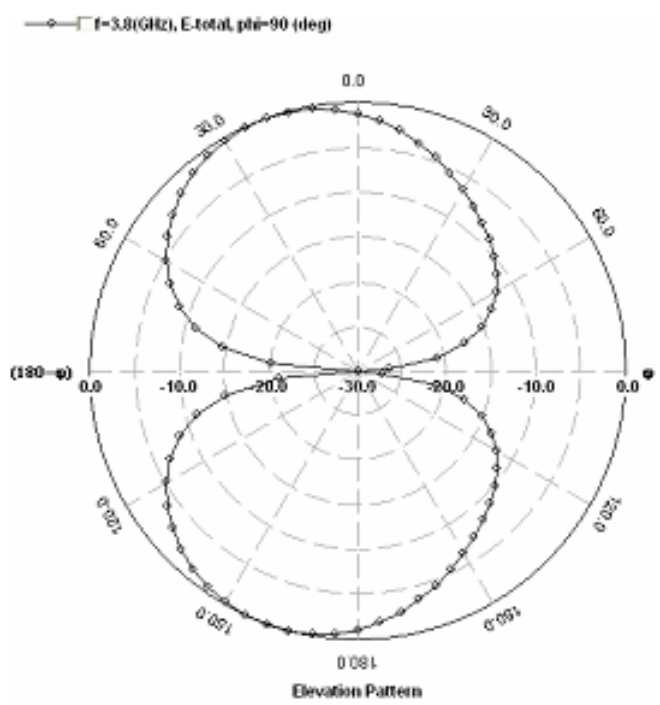

(a)

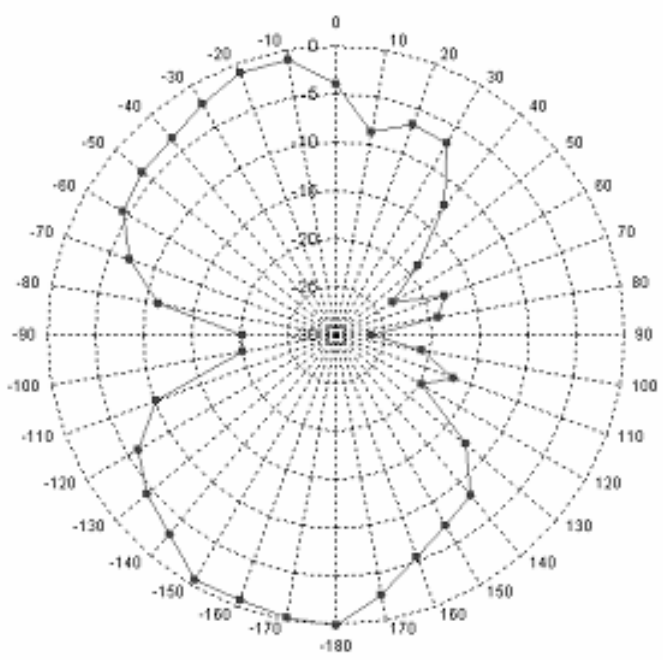

(b)

Fig.7. H-plane radiation pattern (a) Simulated (b) Measured

\section{REFERENCES}

[1] Jia-Yi Sze and Kin-Lu Wong, "Bandwidth Enhancement of a Microstrip-Line-Fed Printed Wide-Slot Antenna," IEEE Trans. Antennas Propagat. Vol.49, No.7, July 2001, Pg.1020

[2] Horng-Dean Chen, "Broadband CPW-Fed Square Slot Antennas with a Widened Tuning Stub, "IEEE Trans. Antennas Propagat. Vol.51,No.8,Aug 2003, Pg.1982.

[3] A.A Kishk and K.F. Lee, "Ultra wide-band Coplanar Waveguide-Fed Rectangular Slot Antenna", IEEE Trans Antennas Propagat., vol. 3,2004, Pg.227

[4] IE3D, Users Manual Zeland Software. Inc. 


\section{AUTHORS PROFILE}

T. Shanmuganantham was born May 12, 1974. He received B.E. degree in Electronics and Communication Engineering from University of Madras in 1996, M.E. degree in Communication Systems from Madurai Kamaraj University in 2000 and Ph.D. degree (Gold Medal) in the area of Antennas from National Institute of Technology, Tiruchirappalli, India under the guidance of Dr.S.Raghavan, Professor of ECE. He has 15 years of teaching experience in various reputed Engineering colleges such as SSN College of Engineering, Chennai, National Institute of Technology and Science, Chennai, PKIET, Karaikal. He has been with the Department of Electronics Engineering, School of Engineering \& Technology, Pondicherry University, Pondicherry as an Assistant Professor since 2010. His research interest includes Antennas, Microwave \& Millimeter-wave Engineering, Microwave Integrated Circuits, MEMS/NEMS, Metamaterials, Computational Electromagnetics, EMI/EMC, RF MEMS, RFIC Design, Optical Communication, Soft Computing for RF \& Microwave Engineering, Terahertz Technology. He has published 40 research papers in various national and International level Journals and Conferences. He is a member in IEEE, Life Member in IETE, Institution of Engineers, CSI, Society of EMC, ISTE, ISSS, OSI, ISI and ILA.

Dr.S.Raghavan having 32 years of Teaching (U.G., P.G. and Research) experience in the National Institute of technology, Tiruchirappalli, India as a Senior Professor. Developed Microwave and Microwave Integrated Circuits Lab. Obtained B.E.(Electronics and Communication Engineering) degree from College of Engineering , Guindy. M.Sc. (ENGG.) Microwave Engineering from College of Engineering, Trivandrum and Ph.D.(Microwave Integrated Circuits) from I.I.T., Delhi, India under the guidance of Prof.Baharathi Bhat and Prof.S.K.Koul. Senior Member of IEEE in MTT and EMBS. Life Fellow in BES. Fellow in IETE and IE, Life member in ISSS, MRSI, ISTE, EMC/EMI, IELTS and ILA. Referee for MTT journal. Carried out two Research and Development projects of Coplanar Waveguide and RFMEMS. Has contributed more than 300 papers in international Conferences and 100 papers in international Journals. Conducted more than 10 tutorials in IEEE preconference tutorials. 